\title{
A Systematic Analysis of the Vulnerability of Buildings to Localised Collapse
}

\author{
V. Janssens and D.W. O'Dwyer \\ Department of Civil Engineering \\ Trinity College Dublin, Ireland
}

\begin{abstract}
This paper presents a methodology to assess the extent of damage to a multi-storey structure due to localised collapse. This is accomplished through the design of an algorithm, to track progressive collapse in a structure, and its implementation as a computer program. This program is based on the alternative path method of analysis, and involves systematically removing individual elements from the structure following their failure. The algorithm works by increasing the applied load and monitoring the formation of plastic hinges, and the development of unstable compression members. The formation of such mechanisms can cause localised damage or may lead to progressive collapse. By systematically considering the effects of damage to all members in a structure, the algorithm can identify whether a structure is unduly sensitive to the effects of localised damage.
\end{abstract}

Keywords: robustness, progressive collapse, accidental actions, elasto-plastic analysis, alternative load path, structural reliability, vulnerability analysis.

\section{Introduction}

Progressive collapse is defined by ASCE 7-05 [1] as "the spread of an initial local failure from element to element resulting, eventually, in the collapse of an entire structure or a disproportionately large part of it". More generally, progressive collapse is characterised by the loss of load-carrying capacity, of a relatively small portion of a structure. This initial damage triggers a cascade of failures, affecting a major proportion of the structure. It is worth noting that the definition of progressive collapse is something that is under constant discussion within the engineering community, and that no single definition of the term exists at present. However, for the purpose of this paper the definition provided in ASCE 7-05 will be used. A collapse of this nature can be triggered by a many causes; including design and construction errors, as well as loading conditions with a low probability of 
occurrence (e.g. gas explosions, vehicular collisions). However, the unforeseen nature of these events presents the designer with a significant challenge when trying to improve structural safety.

Due to recent developments in computerised design, and high-performance materials, modern structures are more optimised than their predecessors. However, this optimisation has led to a reduction in the inherent margin of safety. The result of this is that modern structures have little excess capacity to resist unforeseen loading conditions. Therefore, modern structures are more vulnerable to unforeseen loading conditions. Gross and McGuire [2] suggest that this increased vulnerability can also be attributed to new construction methods which aim to reduce costs, but lack the strength and continuity of traditional forms of construction. Additionally, the increased threat of terrorism worldwide has highlighted the need to consider hazards that may not have been viewed as significant in the past. One of the most serious risks associated with this increased vulnerability is the risk of collapse. Although this is a significantly rare event, it is widely appreciated that, regardless of the triggering event, structural collapse is the principal reason for injury and death in building failures [3]. Therefore, the incorporation of rational procedures for mitigating the potential for collapse must be incorporated into the design of all structures.

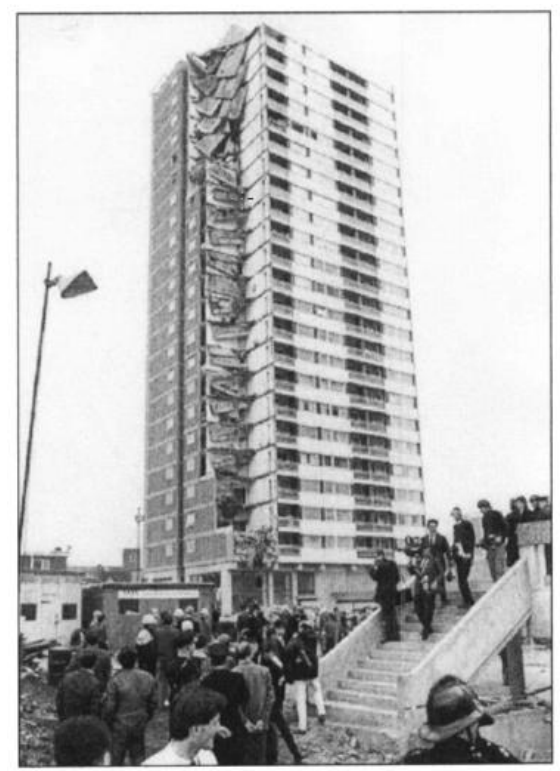

Figure 1: Ronan Point apartment tower after collapse.

The intellectual debate on progressive collapse, and the robustness of structures, was initiated following the partial collapse of the Ronan Point apartment tower. Ronan Point was a 22-storey residential apartment tower, constructed using loadbearing precast concrete panels [4]. On the morning of May 16, 1968, a minor gas explosion, on the $18^{\text {th }}$ floor, blew out the exterior walls of the apartment. This triggered a progression of failure that resulted in the collapse of the southeast corner 
of the tower. As a result of this event, and the consequent report of the Commission of Inquiry, a number of countries (including the UK and Canada) implemented provisions to minimise the potential for progressive collapse. The terrorist attack on the Murrah Federal Office Building [5], in 1995, marked the start of a second wave of interest in the topic. Following the collapse of the World Trade Centre Twin Towers, and the nearby World Trade Centre 7 building, due to the events of September $11^{\text {th }}, 2001$, interest in this subject appears to have reached its peak. Numerous publications on progressive collapse and extreme loading have appeared in the literature over recent years, and a number of guidance documents have been published by regulatory authorities to assist design professionals in designing progressive collapse resistant structures [6-8].

\section{Methods of Improving Progressive Collapse Resistance}

As building designers cannot possibly design for every hazard that a building may be subjected to in its lifetime, a general design approach is required to account for the risks associated with low-probability high-consequence events. There are, in general, three alternative approaches to designing structures to resist progressive collapse:

- Improved interconnection or continuity;

- Alternative load path method; and

- Improved local resistance.

These approaches are normally classified in terms of indirect and direct design approaches.

\subsection{Indirect Design}

Indirect design approaches consist of various prescriptive measures of improving the robustness of a structure. This method has the advantage that it can be implemented without the need for any additional analysis. This is a significant advantage when dealing with unforeseen loading conditions, and therefore indirect design methods are incorporated into most codes and guidelines. When applying this approach, the overall structural robustness is increased by adopting general methods of improving structural integrity, throughout the design process. The provisions found in the design codes and guidelines are usually in the form of prescriptive requirements for minimum joint resistance, continuity and tying between the members.

With special reference to the tying force requirements, the underlying philosophy is that if all members are connected by joints with a specified capacity, the selected structural configuration will have adequate strength to resist progressive collapse. Hence, the structural elements should be effectively tied together to allow redistribution of the gravity loads following a local failure. In general, both horizontal and vertical ties should be considered, the capacities of which are determined separately to the design loads. Additionally, horizontal ties should be arranged in continuous straight lines and distributed throughout the plan of each 
floor in two directions, at approximately right angles, and vertical ties should be continuous from the lowest to the highest level of the building [9].

Due to its ease of implementation, indirect design methods are favoured, and have been incorporated into most major building codes $[1,6,7,9]$. However, these approaches give no consideration to how a structure should behave if local damage occurs, and therefore may not actually increase the resistance of a structure to progressive collapse [10]. Therefore, it is advised that these techniques are only used for standard structural configurations, and that a more detailed analysis would be carried out for complex or high occupancy structures [11].

\subsection{Direct Design}

In contrast, the direct design approach relies heavily on structural analysis and can benefit significantly from the use of sophisticated analysis techniques; such as nonlinear and/or dynamic analysis. Two commonly applied approaches to reduce the potential for progressive collapse are; the alternative load path method and the specific local resistance method. The alternative load path method requires a structure to be designed so that it can bridge across local failure, resulting from sudden loss of a primary load carrying member. While, the specific local resistance method increases the strength of key elements to resist failure under certain specified loading conditions.

\subsubsection{Specific Local Resistance}

The specific local resistance method requires that critical load carrying components are designed to withstand a specified level of threat, which may be in the form of blast, impact or fire loading. As a result, the structure is provided with additional strength at areas that are believed to be prone to accidental loads (e.g. exterior columns at risk from vehicular collision), or in key elements that are crucial to the overall structural stability. In the case of designing key elements, they should be able to develop their full resistance against an unanticipated load without failure of either the member itself or its connections. By activating the full resistance available in the key members, this approach maximizes their ability to deal with unforeseen hazards without having to redistribute loads. Hence, detailing of these elements should aim at developing the ultimate capacity of the materials under axial, shear and bending actions by means of confinement and continuity of the reinforcement for reinforced concrete construction, and encasement or stiffeners for steel construction [9].

The specific local resistance method is the procedure favoured by the current codes and guidelines [10]. However, this is a threat specific approach, which is a significant disadvantage of this technique over the alternative path method. One of the issues features of designing to resist progressive collapse is that the loading events in question are outside the scope of normal design. Due to the unforeseen nature of these events, we cannot accurately predict their magnitude and location. 
Therefore, a threat-dependant design cannot guarantee that the building will perform adequately for events other than the one specifically considered [11].

\subsubsection{Alternative Load Path Method}

The alternative load path method was initially recommended following significant research during the 1970's [12]. This design approach focuses on the behaviour of a structural system following the occurrence of an extreme event, and requires the structure to redistribute the loads following loss of a primary load bearing member. The basic procedure followed in any alternative path analysis involves removal of one, or several, primary structural components from the structure. The altered structure is then analysed to determine if the initiating damage propagates. This method promotes the use of regular structural configurations that exhibit ductility and energy absorption properties, which are desirable features for mitigating the risk of progressive collapse.

One of the main advantages of this technique is that it is a threat independent approach, and therefore, is valid for any hazard that may cause failure. This avoids one of the main difficulties faced by engineers in designing structures to resist progressive collapse; attempting to quantify an otherwise unknown loading event. The design guidelines produced by the Department of Defence [6] and the General Services Administration [7], in the United States, both recommend the use of this technique, and identify four alternative analytical approaches, of increasing complexity; linear static, nonlinear static, linear dynamic and nonlinear dynamic analysis.

This paper implements a variation of the nonlinear static approach, however, a summary of all approaches is provided, for completeness.

\section{Linear Static Analysis}

The simplest form of the alternative load path method involves performing a linear static analysis on the damaged structure. This involves applying the fully factored gravity loads, in a single step, to the damaged structure. The proceeding analysis is based on the assumption of small deformations. Dynamic effects can be indirectly considered by assuming an equivalent static load based on a constant amplification factor typically taken equal to 2.0 [6-7].

\section{Nonlinear Static Analysis}

Nonlinear static analysis improves on linear static analysis through inclusion of both geometric and material nonlinearities in the procedure. The inclusion of these nonlinearities is required to account for catenary/membrane effects, as well as to allow for accurate representation of inelastic response and the effects of the P- $\Delta$ effects.

Similar to the linear static approach, the nonlinear static approach applies a dynamic amplification factor, to simulate the impact of falling debris. However, the 
gravity loads are not applied in one step, but instead a vertical pushover analysis is employed. This involves incremental application of the loads until the maximum loads are attained or collapse occurs, and further improves the accuracy of the structural model.

\section{Linear Dynamic Analysis}

Because load redistribution effects will occur dynamically during an abnormal loading event, dynamic effects are important considerations when attempting to accurately represent structural behaviour, in a progressive collapse analysis. Linear dynamic (or time-history) analysis explicitly accounts for these effects, but is unable to capture the nonlinear behaviour. Hence, although its implementation is easier compared to nonlinear dynamic analysis, this method requires extensive judgment on the part of the designer to establish whether P- $\Delta$ and membrane effects are significant and to determine whether the computed results are realistic.

\section{Nonlinear Dynamic Analysis}

The most rigorous approach for carrying out an alternative path analysis is through the use of nonlinear dynamic analysis. This method dynamically removes a member from the structure, which is then analysed taking account of both the geometric and material nonlinearities. This allows larger deformations and energy dissipation through material yielding, cracking and fracture [13]. More complex nonlinear dynamic analyses may also include dynamic effects, due to the impact of failed members on other portions of the remaining structure [14].

It is important to emphasise that the analysis of a structure in a severely damaged state is a complex problem. The alternative path method is not intended to precisely model the progressive failure process, but to assist engineers in designing more robust structures. Therefore, it is possible to use the simpler procedures described above, but an experienced engineer with considerable knowledge and experience in structural modelling is essential, to ensure accuracy of the results

\section{Modelling Progressive Collapse}

For the purpose of this paper, a static analysis program capable of following the sequence of failures that occur during a progressive collapse has been developed. This program implements the finite element method, and incorporates material nonlinearities through the formation of plastic hinges. The algorithm works by increasing the applied load, and monitoring the formation of plastic hinges and unstable compression members. Following their failure, individual elements are removed and the altered structure is re-analysed. This process continues until global failure of the structure occurs, or equilibrium is reached for the required loading conditions. The following figure outlines the algorithm implemented in this program. 


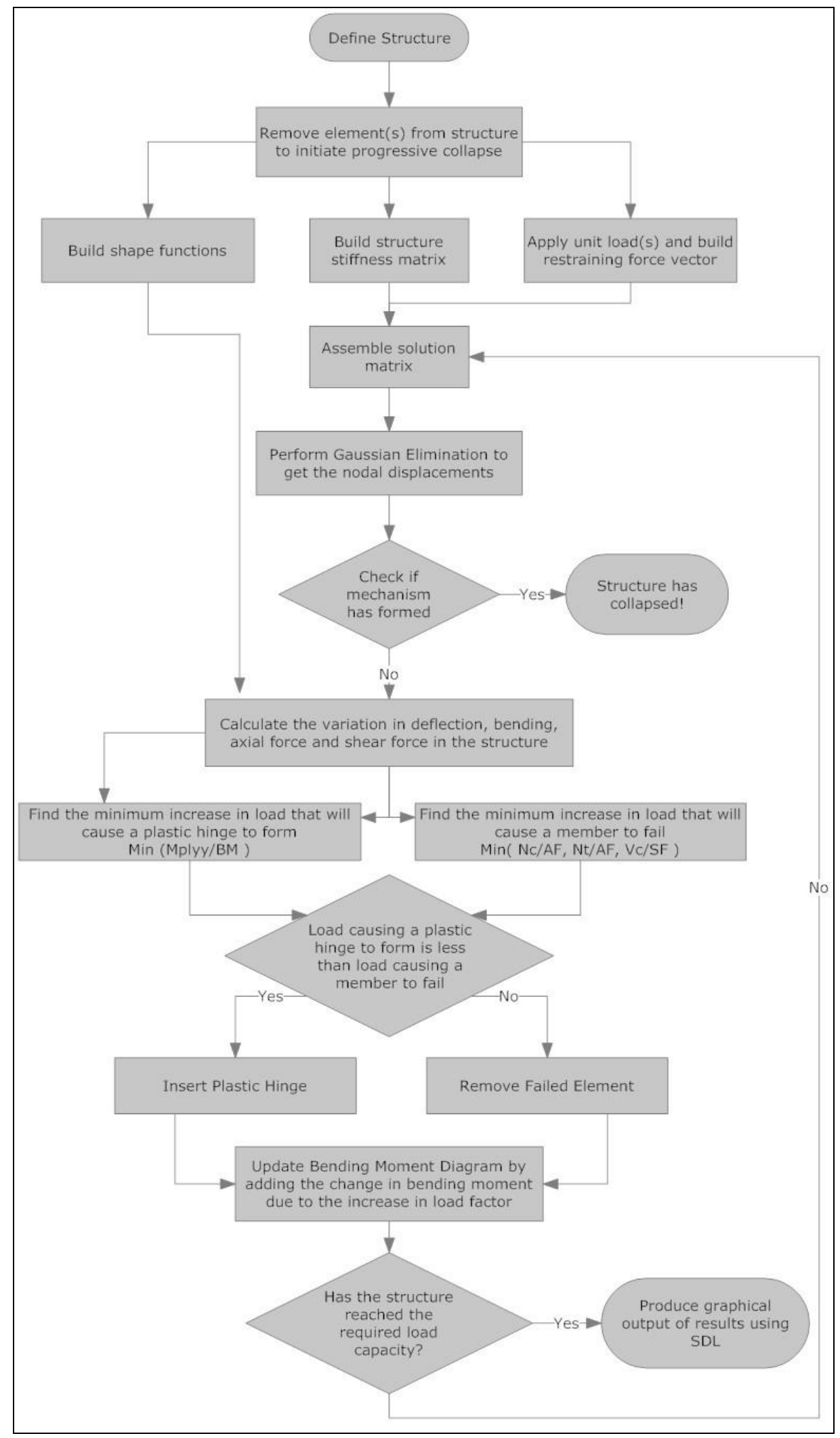

Figure 2: Flowchart describing progressive collapse algorithm. 


\section{Case Study: Progressive Collapse Analysis of 2D Frame}

The following case study demonstrates the application of the progressive collapse program described in the preceding section. The behaviour of the two-storey frame shown in Figure 3 is analysed, following the removal of the central ground floor column (highlighted in red). Local failure of this nature is consistent with that caused by a minor gas explosion or vehicular collision. However, as mentioned previously, collapse of this nature is usually initiated by unforeseen loading conditions. This presents the designer with the difficulty of attempting to quantify the extent of initial damage following an unknown event. For this reason, it is advisable that for a comprehensive progressive collapse analysis a wide range of initiating events should be considered, including the removal of multiple elements and the removal of elements at various locations throughout the structure.

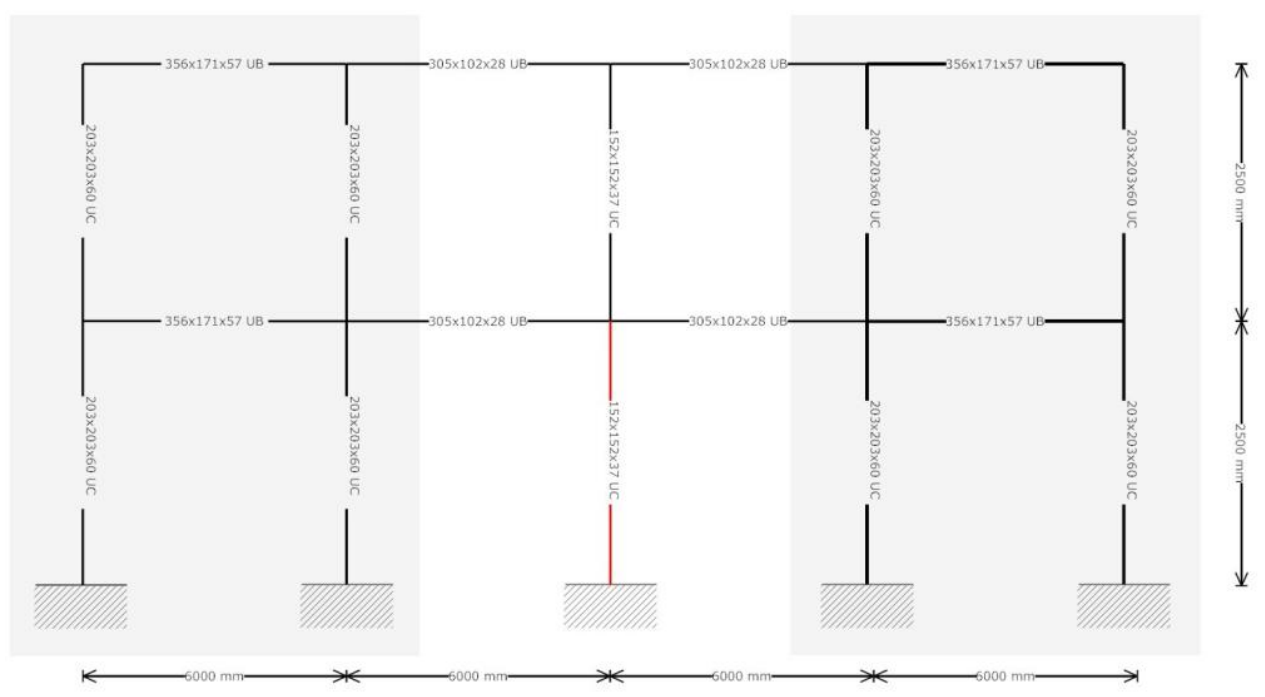

Figure 3: Frame for analysis using progressive collapse program.

The structure analysed is subjected to a uniformly distributed load, of magnitude $26.7 \mathrm{kN} / \mathrm{m}$, across the entire floor area. Initially, the structure was analysed using the optimal section sizes for the required loading conditions. However, removal of the central column initiated global collapse of the structure, when less than half of the required loading was applied to the structure. Therefore, it was decided to increase the capacity of the corner bays (shaded portions). By increasing the sections sizes used, the robustness of the structure is increased, and hence a reduction in the extent of collapse will be observed.

Table 1 (following page) provides the capacities of the sections that were chosen for the structure. It is worth noting that the capacity of both the corner beams and the corner columns was more than doubled due to the increased section sizes. This 
increase enables the structure to absorb the large rotations that can be expected during a progressive collapse sequence.

\begin{tabular}{|l|r|r|r|}
\hline Section Size & $\mathrm{M}_{\mathrm{p}}(\mathrm{kNm})$ & $\mathrm{N}_{\mathrm{c}} / \mathrm{N}_{\mathrm{t}}(\mathrm{kN})$ & \multicolumn{1}{c|}{$\mathrm{V}_{\mathrm{c}}(\mathrm{kN})$} \\
\hline 152x152x37 UC & 84.98 & 1295 & 226.1 \\
203x203x60 UC & 180.4 & 2101 & 352.2 \\
$305 \times 102 \times 28$ UB & 110.8 & 987.3 & 315.2 \\
$356 \times 171 \times 57 \mathrm{UB}$ & 277.8 & 987.3 & 315.2 \\
\hline
\end{tabular}

Table 1: Capacities for the section sizes used in the analysis

The progressive collapse sequence is initiated by the instantaneous removal of the ground floor column. Following this, the loading on the structure is gradually increased, and the structure is monitored for the formation of plastic hinges and unstable compression members. The resulting bending moment diagram, immediately following the column removal, is shown in figure 4 .

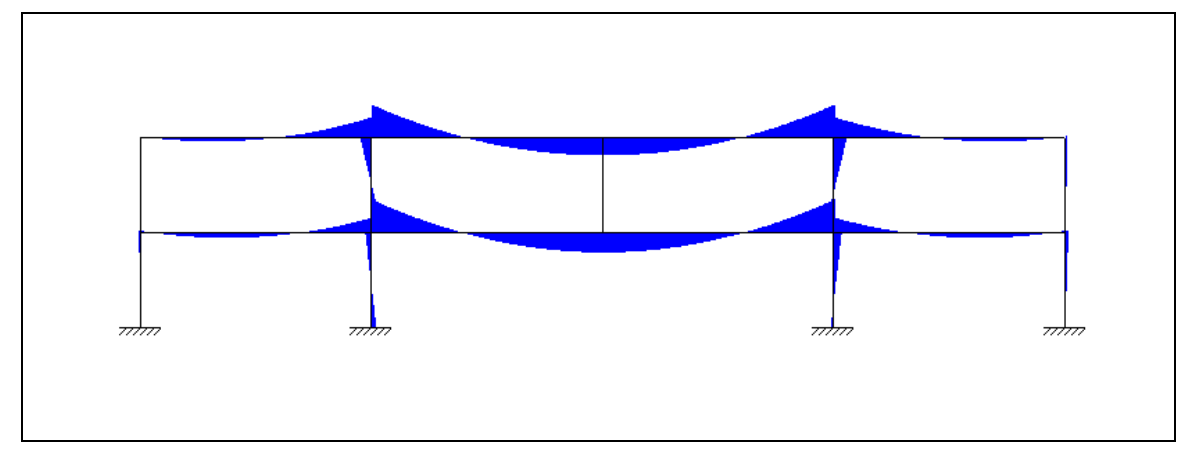

Figure 4: Bending moment diagram following column removal.

As the loading on the structure is increased, plastic hinges begin to form at the ends of the first and second floor beams, in the central two bays of the structure. Following the formation of these hinges, significant bending occurs in the centre of these beams. The large rotations associated with plastic bending can also be seen to induce significant loads in the corner bays. The large bending moments in the beams, and the significant axial forces in the columns, caused by these rotations were the cause of global failure of the structure for the fully stressed design. As the loading continues to increase, additional plastic hinges form at the centre of the first and second floor beams, in the centre of the structure. This results in the formation of unstable beam mechanisms, and therefore, the failure of these bays of the structure.

Following failure of the central portion of the structure, the loading is gradually increased to the required level. Figure 5 (below) shows the results of the progressive collapse analysis once the structure has reached equilibrium. This illustrates the benefits of increasing the member sizes for the corners. These bays have remained intact, although large bending moments have been induced in the beams, and large 
forces in the columns. However, the increased cost associated with such an increase in member sizes may discourage some designers. Therefore, alternative techniques of improving the robustness of a structure must be developed, with particular reference to the corner bays of multi-bay structures.

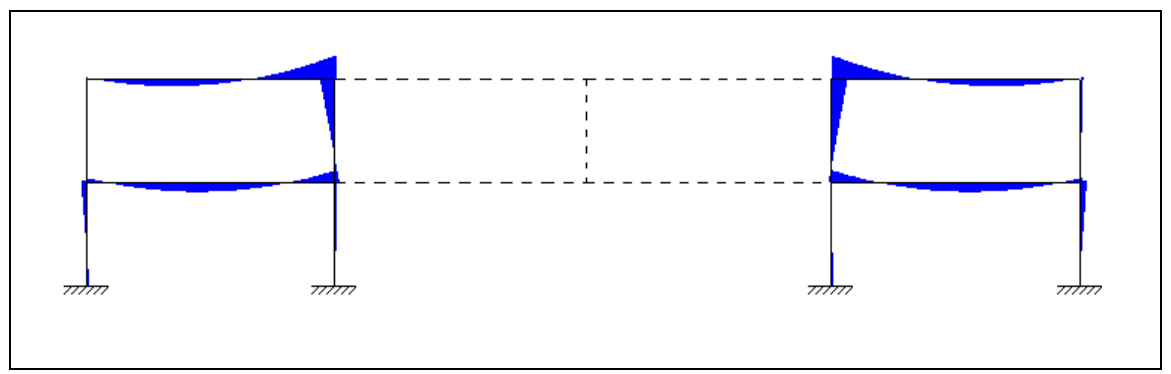

Figure 5: Bending moment diagram for structure at end of analysis

\section{Conclusions}

This paper has presented a methodology to analyse the vulnerability of a structure to progressive collapse. The computer program developed can be used both as a design and an analysis tool, providing a simple method of assessing both existing and new buildings. The program allows the user to predict the extent of collapse following certain initiating events, and to identify vulnerable structural configurations (e.g. weak corner bays as illustrated in the case study) which should be addressed. Therefore, software of this nature is a key tool for engineers when ensuring a structure possesses adequate excess capacity to resist the effects of unforeseen loading conditions.

It is worth highlighting that this program is in the early stages of development, and there are a wide range of possible modifications for inclusion in future versions of the analysis program. At present, no load redistribution effects are considered following the failure of an element. However, in order to detect the propagation of failure due to load shedding, similar to that seen in the Ronan Point collapse, the effects of the impact of failed members on the floors below should be addressed. Also, the effects of geometric nonlinearities can be significant during progressive collapse, and hence the effects of moments caused by lateral displacements require some consideration.

\section{Acknowledgments}

This research is supported by the Irish Research Council for Science Engineering and Technology (IRCSET) Embark Initiative. 


\section{References}

[1] American Society of Civil Engineers. "Minimum Design Loads for Buildings and Other Structures". ASCE 7-05. Reston, Virginia, 2005.

[2] J.L. Gross and W. McGuire. "Progressive Collapse Resistant Design". Journal of Structural Engineering. 109(1), 1-15, 1983.

[3] National Research Council. "Protecting People and Buildings from Terrorism: Technology Transfer for Blast-effects Mitigation". Washington, DC, 2001.

[4] C. Pearson and N. Delatte. "Ronan Point Apartment Tower Collapse and its Effects on Building Codes". Journal of Performance of Constructed Facilities. 19(2), 172-177, 2005.

[5] J.D. Osteraas. "Murrah Building Bombing Revisited: A Qualitative Assessment of Blast Damage and Collapse Patterns". Journal of Performance of Constructed Facilities. 20(4), 330-335, 2006.

[6] Department of Defence (DoD). "Unified Facilities Criteria - Design of Building to Resist Progressive Collapse". UFC 4-023-03. Washington, DC, 2005.

[7] General Services Administration (GSA). "Progressive Collapse Analysis and Design Guidelines for New Federal Office Buildings and Major Modernization Projects". Washington, DC, 2003.

[8] Standing Committee on Structural Safety (SCOSS). "16th Biennial Report". London, 2007.

[9] A.A. Vlassis. "Progressive Collapse Assessment of Tall Buildings", Civil and Environmental Engineering, University of London - Imperial College London, London, 2007.

[10] British Standards Institution (BSI). "Eurocode 1 - Actions on Structures - Part 1-7: General actions - Accidental actions". BS EN 1991-1-7:2006. London, 2006.

[11] B.R. Ellingwood. "Mitigating Risk from Abnormal Loads and Progressive Collapse". Journal of Performance of Constructed Facilities. 20(4), 315-323, 2006.

[12] G. Kaewkulchai and E.B. Williamson. "Beam Element Formulation and Solution Procedure for Dynamic Progressive Collapse Analysis". Computers \& Structures. 82(7-8), 639-651, 2004.

[13] S.M. Marjanishvili and E. Agnew. "Comparison of Various Procedures for Progressive Collapse Analysis". Journal of Performance of Constructed Facilities. 20(4), 365-374, 2006.

[14] G. Kaewkulchai and E.B. Williamson. "Modelling the Impact of Failed Members for Progressive Collapse Analysis of Frame Structures". Journal of Performance of Constructed Facilities. 20(4), 375-383, 2006. 